\title{
On-farm evaluation of pinhole castration for mass castration of goats and cattle in pastoral communities of central Uganda
}

\author{
J Okwee-Acai*, G Bigirwa, JS Onyait, B Agwai and J Acon \\ Department of Veterinary Pharmacy, Clinical and Comparative Medicine, School of Veterinary Medicine and \\ Animal Resources, P. O. Box 7062 Makerere University, Kampala
}

\begin{tabular}{|l|l|}
\hline $\begin{array}{l}\text { Article history } \\
\text { Received: 24 Oct, 2015 } \\
\text { Revised: 10 Feb, 2016 } \\
\text { Accepted: 21 Feb, 2016 }\end{array}$ & $\begin{array}{l}\text { Abstract } \\
\text { Pinhole castration is described as simple, cheap and minimally invasive alternative to } \\
\text { conventional surgical castration. We evaluated effectiveness, associated costs and } \\
\text { animal's systemic responses during mass castration of kids and calves in pastoral } \\
\text { communities of central Uganda. Kids (n=112) and calves (n=201) routinely presented } \\
\text { to community practitioners were castrated using pinhole technique. Rectal temperature } \\
\text { and appetite was noted for six consecutive days after castration. Sixty days later, the } \\
\text { testes were observed for evidence of gross atrophy. Testes showing gross changes } \\
\text { were recovered by knife castration for histopathology. The mean age of kids was 3-4 } \\
\text { months, while calves were about a year or older. Each pinhole procedure lasted for 7-8 } \\
\text { min and consumed 10-15 cm of suture; costing 0.3-0.4 US dollars. Following } \\
\text { castration, there was significant (t =-3.46; P<0.05) rise in mean rectal temperature } \\
\left.\text { (39.7 }{ }^{\circ} \mathrm{C}\right) \text { in both kids and calves for 3-5 days. About 5\% of castrated animals showed } \\
\text { unilateral or bilateral noatrophy; however, 94\% of these were actually hydrocele with } \\
\text { dysfunctional testes. In conclusion, pinhole castration is an effective, minimally } \\
\text { invasive, cheap and simple alternative for mass castration of kids and calves. However, } \\
\text { efficacy of the technique should be investigated further in calves that are about a year } \\
\text { of age. } \\
\text { Keywords: Pinhole technique; mass castration; pastoral communities; Uganda }\end{array}$ \\
\hline
\end{tabular}

To cite this article: Okwee-Acai J, G Bigirwa, JS Onyait, B Agwai and J Acon, 2016. On-farm evaluation of pinhole castration for mass castration of goats and cattle in pastoral communities of central Uganda. Res. Opin. Anim. Vet. Sci., 6(1): 13-18.

\section{Introduction}

Castration is the oldest and commonest operative procedure in veterinary practice (Ames, 1988; Wu, 1988). Male animals are usually castrated for the purposes of breeding control, behaviour modification and reduction of malodour (taint) in carcasses (Coetzee et al., 2010).

To date, complete removal of the testes, also called knife castration is the preferred castration technique
(Wu, 1988). Alternatively, clumping or crushing the spermatic cords to cause testicular necrosis in situ is sometimes applied; especially in mass castration of kids or bull calves (Ames, 1988). Unfortunately, these conventional methods inflict severe pain and stress on the animal (Stafford and Mellor, 2005), which is a major animal welfare concern globally (Jana et al., 2005; Ponvijay, 2007).

Besides the welfare concerns, conventional castration methods are also considered expensive,

\footnotetext{
*Corresponding author: J. Okwee-Acai, Department of Veterinary Pharmacy, Clinical and Comparative Medicine, School of Veterinary Medicine and Animal Resources, P. O Box 7062 Makerere University, Kampala; E-mail: jokwee@ covab.mak.ac.ug /jokwee@yahoo.co.uk
} 
laborious and too technical for mass application in resource poor communities (Prunier et al., 2006). There is therefore, an increasing emphasis on the need to develop alternative castration techniques like pinhole castration, which is simple, cheap and less stressful.

Pinhole castration or in situ spermatic cord ligation is a promising and widely recommended alternative to conventional castration (Ponvijay, 2007; Okwee-Acai et al., 2013; Baba et al., 2013; Abid and Al-Baghdady, 2013). The technique is effective, simple, economic and minimally invasive compared to conventional castration approaches. Pinhole technique has however been tested mainly in controlled experiments. Its effectiveness and suitability for mass application in farming communities is not tested. This study evaluated pinhole castration technique for its effectiveness, associated costs and the animal's systemic responses during mass castration of kids and calves in pastoral communities of central Uganda.

\section{Materials and Methods}

\section{The study area}

The evaluation was conducted on farms in Sembabule $\left(00^{\circ} 06^{\prime} \mathrm{S} ; 31^{\circ} 30^{\prime} \mathrm{E}\right)$ and Kiboga $\left(01^{\circ} 00^{\prime} \mathrm{N}\right.$ $\left.31^{\circ} 46^{\prime} \mathrm{E}\right)$ Districts of Central Uganda.. The farming communities in the districts are largely agro-pastoral. In this extensive farming system, kids or calves are routinely castrated to promote selective breeding.

\section{Animals}

Animals (201 calves and 112 kids) were presented for castration to local animal health practitioners within the communities. An informed consent was obtained from the animal owners before inclusion of the animal in the study. Prior to the study, the practitioners underwent training on the protocol for this study and the pinhole procedure. These were called novice practitioners as compared to the experienced research team. A total of 201 calves were castrated of which 93\% (187) were Zebu-Friesian crosses and 14 were indigenous Zebu. Of the 112 kids castrated, 67 (60\% were Boer crosses with the small east African goat (SAE) while 45 (40\%) were pure SAE.

\section{The pinhole procedure}

On each kid or calf, pinhole castration was performed as per the procedure described by Ponvijay (2007). Each spermatic cord was ligated using polygalactin 910 (Vicryl®, Johnson and Johnson, UK) sutures of size 4 metric. These were threaded through 1.5 inch; 18 gauge hypodermic needle (TERUMO®, USA). The needles and suture strands were thoroughly disinfected in chlorhexidine (Germilon ${ }^{\circledR}$, AFRO-ASIA Ltd, Kampala, Uganda) in case of reuse. The duration of each pinhole procedure (cord ligation) was recorded.

\section{Estimation of costs}

The amount of Vicryl ${ }^{\circledR}$ consumed was estimated by subtracting the length of suture remaining after each pinhole procedure form the original suture length. Since, suture material was the major consumable, the material cost of each castration procedure was taken to be equal to the cost of the Vicryl ${ }^{\circledR}$ consumed in each case. In the Ugandan market, a $75 \mathrm{~cm}$ strand of Vicryl ${ }^{\circledR}$ was valued at 2 US Dollars (\$).

\section{Monitoring of castrated animals}

To assess stress, rectal temperature of each kid or calf was taken just before the pinhole procedure then daily for 6 consecutive days. Additionally, each kid or calf was observed daily for at least an hour during grazing for changes in demeanour and/or appetite (Molony et al., 1995). Sixty days after pinhole procedure, castrated animals were restrained and examined for gross testicular atrophy. Castrated kids or calves showing gross testicular changes were subjected to knife castration (Ames, 1988) to recover the testes. Thirty testes were grossly examined before fixing in $10 \%$ buffered formalin for histopathology (Anderson and Smith, 2003).

\section{Results}

Mean duration of pinhole castration in kids and calves

As shown in figure 1, each pinhole procedure took about 6.97 minutes in kids and 7.92 minutes in calves. However, experienced practitioners took significantly $(\mathrm{z}=2.41, \mathrm{P}<0.05)$ less time (about 3 minutes) compared to novice practitioners (Table 1). Though not statistically significant $(\mathrm{P}>0.05)$, time taken to complete cord ligation decreased with increasing age or weight of the animal.

\section{Material requirement and cost of pinhole castration in kids and calves}

On average, each pinhole procedure consumed $10 \mathrm{~cm}$ of Vicryl ${ }^{\circledR}$ per kid and $15 \mathrm{~cm}$ per calf with mean cost of 0.3 and 0.4 US Dollars respectively (Fig. 2). The cost of castration significantly $(\mathrm{t}=24.82 ; \mathrm{P}<0.05)$ increased with age of the animal (Table 2).

\section{Changes in rectal temperature following pinhole}

There was a marked rise in mean rectal temperature following pinhole castration in both kids and calves compared to pre-treatment values (Fig. 3). In kids, mean rectal temperature was highest (39.7) by the second day after treatment and gradually decreased to pre-treatment value $(38.7)$ by the $5^{\text {th }}$ day after treatment. In calves, the temperature rose to $39.6^{\circ} \mathrm{C}$ a day following treatment and gradually fell to pretreatment value $\left(38.5^{\circ} \mathrm{C}\right)$ by the $3^{\text {rd }}$ day after pinhole 


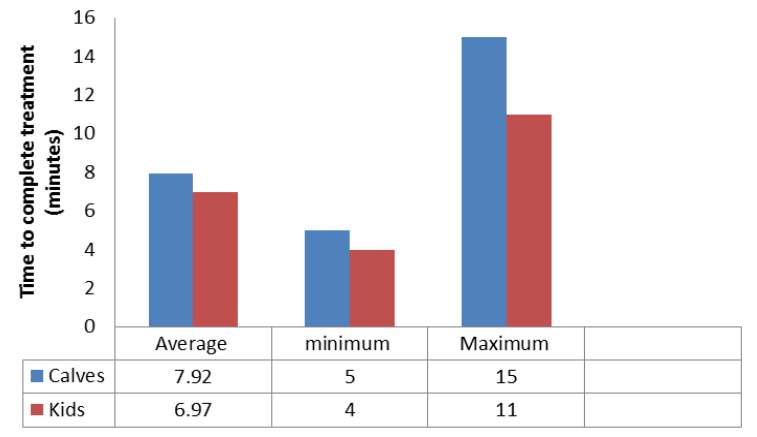

Fig. 1: Mean duration of pinhole castration in kids and calves
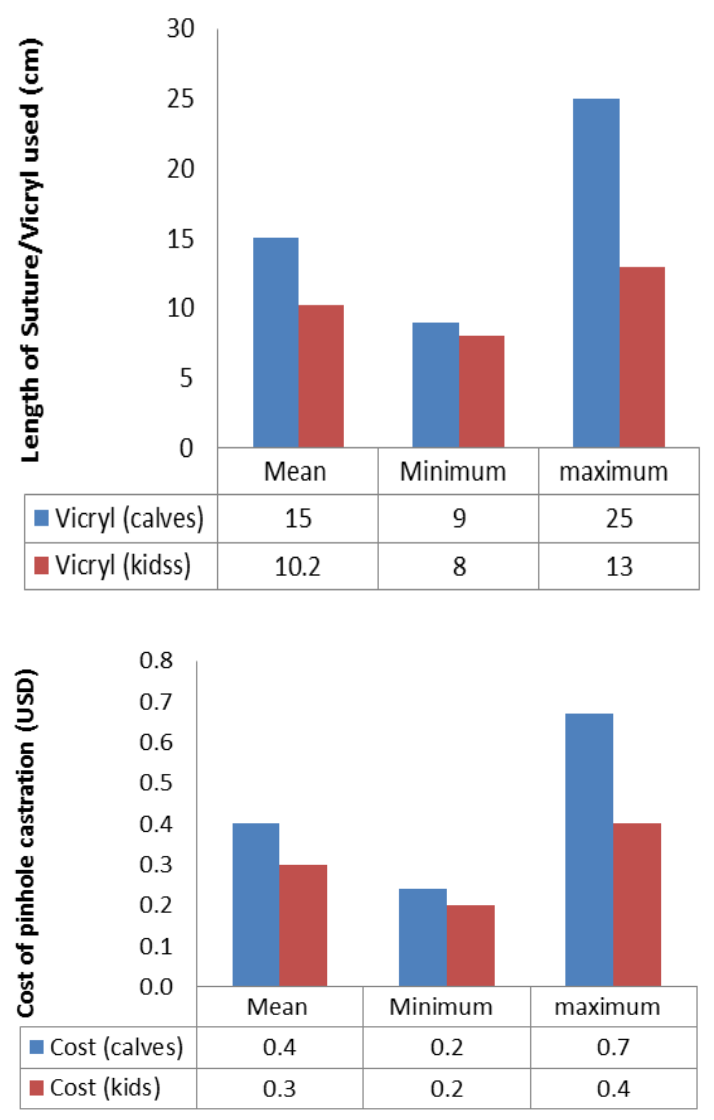

Fig. 2: Material requirement and cost of pinhole castration in kids and calves

Table 1: Factors affecting completion of pinhole treatment

\begin{tabular}{lcccc}
\hline & $\begin{array}{c}\text { Estimate } \\
\text { (minutes) }\end{array}$ & $\begin{array}{c}\text { Std. } \\
\text { Error }\end{array}$ & z-value & $\begin{array}{c}\text { P- } \\
\text { Value }\end{array}$ \\
\hline Intercept & 6.97 & 1.30 & 5.41 & $<0.01$ \\
Practitioner & -2.57 & 1.06 & -2.41 & $0.02 *$ \\
experience & & & & \\
Age of goat & -0.06 & 0.12 & -0.50 & 0.61 \\
Weight of goat & -0.01 & 0.01 & -1.04 & 0.29 \\
\hline
\end{tabular}

*experience of practitioner significantly affected duration of pinhole procedure. treatment. As shown in Table 3 for kids, the rise in rectal temperature following pinhole treatments was significantly $(\mathrm{t}=-3.46, \mathrm{P}<0.05)$ higher relative to pretreatment values.

\section{Changes in appetite in kids and calves after pinhole treatments}

One day after pinhole treatment, up to $21 \%$ of the kids had reduced appetite (Fig. 4). The number of kids showing reduced appetite kept declining every day until day 6 where about $2 \%$ of treated kids showed reduced appetite. A day after treatment, $16.4 \%$ of calves had reduced appetite but the number sharply fell such that by the $5^{\text {th }}$ day, all $(100 \%)$ treated calves expressed good appetite.

\section{Gross and histopathological changes following pinhole castration}

Up to $91 \%$ of calves and $98 \%$ of kids showed marked bilateral atrophy of the testes on $60^{\text {th }}$ day after treatment. A total of $5 \%$ of the calves and $0.5 \%$ (1) of kids showed one of the two testes not grossly atrophied i.e., unilateral atrophy (Fig. 5). Similarly, $4 \%$ of the calves and $0.5 \%$ (1) of kids did not show atrophy of both testes. However, $94 \%$ of the seemingly nonatrophied testes, the scrotal sacs were filled with serous fluid and hence were categorized as hydrocele with atrophied testes (Fig. 6). Histologically, all the atrophied testes showed extensive fibrosis of testes losing the normal tubular and interstitial/inter-tubular architecture with absolutely no evidence of spermatogenesis (Fig. 7).

\section{Discussion}

The study showed that the procedure requires 7-8 min per kid or calf to complete a pinhole procedure. In an experiment with Iraqi goats, performing a pinhole procedure was estimated to take even less time, about 4 min (Abdi and Al-Baghdady, 2013). On the other hand, knife (surgical) castration of a calf or kid may take much longer; between 15-35 min (Melches et al., 2007; Okwee-Acai et al., 2012). The short duration required for pinhole castration proves that it is a simple procedure compared to conventional surgery.

On average, each pinhole procedure consumed 10$15 \mathrm{~cm}$ of suture strand (Vicryl ${ }^{\circ}$ ) for kids and calves respectively. Since VIcryl ${ }^{\circledR}$ was the major consumable object, this translated to a total cost of about 0.3-0.4 US Dollars per case. An experimental study evaluating pinhole procedure in dogs reported an average material cost of 1.5US Dollars per case (Okwee-Acai et al., 2012). They further reported that the average cost (5.76 US dollars) for a standard surgical castration in dogs was nearly four times higher than pinhole. The present study thus, demonstrates that pinhole castration is a 


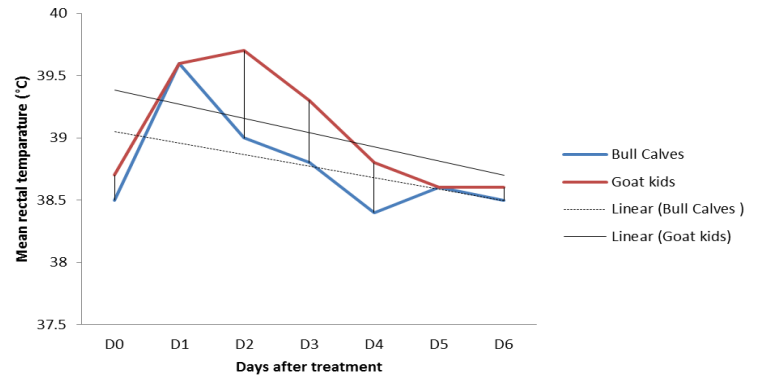

Fig. 3: Changes in rectal temperature following pinhole castration; Key: D0=Day before treatment, D1 to $6=$ Days after treatment

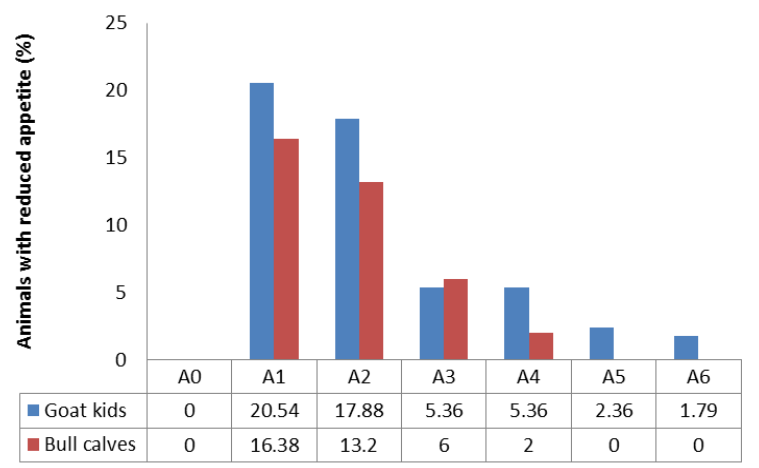

Fig. 4: Changes in appetite in kids and calves after pinhole treatments; Key: $\mathrm{A} 0=\%$ age of animals with reduced appetite before treatments, A1, A2, A3, A4, A5, A6 = $\%$ age showing reduced appetite on days $1,2,3,4,5$ and 6 after treatments.

Table 2: factors affecting cost of castrating kids and calves

\begin{tabular}{lcccc}
\hline Factors & Estimate & Std. Error & t value & P-value \\
\hline Intercept & 9.17 & 0.25 & 37.12 & $<0.001$ \\
Goat Age (months) & 0.46 & 0.02 & 24.82 & $<0.001$ \\
Weight (kg) & -0.02 & -0.02 & -1.08 & 0.280 \\
Practitioner experience & -0.34 & 0.45 & -0.75 & 0.455 \\
\hline
\end{tabular}

Table 3: Effects of pinhole treatments on goat body temperatures

\begin{tabular}{lcccc}
\hline & $\begin{array}{c}\text { Coefficient } \\
( \pm \text { SE })\end{array}$ & $\begin{array}{c}\mathrm{t}- \\
\text { statistic }\end{array}$ & $\begin{array}{c}\text { P- } \\
\text { Value }\end{array}$ & $95 \% \mathrm{CI}$ \\
\hline $\begin{array}{l}\text { Time after treatment } \\
\text { (days) }\end{array}$ & $-0.28 \pm 0.01$ & -3.46 & 0.001 & $-0.04-0.01$ \\
Temperature $\left({ }^{\circ} \mathrm{C}\right)$ & $38.84 \pm 0.35$ & 1121.97 & 0.000 & $38.77-38.92$ \\
\hline
\end{tabular}

much cheaper approach to animal castration compared to conventional surgical approach.

In both kids and calves, pinhole treatment provoked significantly high increase in rectal temperatures compared to pre-treatment values. The temperatures remained high for 3-5 days posttreatment. Also in the current study, changes in appetite showed a similar trend. Previous experimental studies have shown that both surgery and pinhole castration cause acute elevation in rectal temperature within 24-48 hours after treatments, although knife surgery appears to trigger higher inflammatory and febrile response than pinhole castration (Okwee-Acai et al., 2008; Baba et al., 2012). The earlier workers, however, noted that both canines and ruminants castrated by pinhole technique tended to have milder though prolonged stress response as compared to those castrated by standard knife surgery. This could be because pinhole castration, just like intra-testicular injection of sclerotizing agents, cause coagulative necrosis of the testes whose resolution is accompanied by fibrosis similar to secondary intention healing (Baba et al., 2013). On the other hand, a clean surgical incision quickly healed by primary intention (Harari, 2004). The milder febrile, behavioural and stress response to pinhole treatment as compared to knife surgery show that this novel technique is minimally traumatic and can be adopted as an alternative to the standard knife castration technique (Ponvijay, 2007; Baba et al., 2013). Farmers should however be informed that though the pinhole castration is less stressful, animals subjected to the technique may take a little longer recuperating than those surgically castrated.

In this study, about 5\% of pinhole castrated animals showed unilateral or bilateral non-atrophy. Except in donkeys (Abou-Ahmed et al., 2012), this has not been reported previously. It is argued that because equine spermatic cords are very large, it might not be possible to completely cut blood supply to the testes by in situ spermatic cord ligation. In the current study, most of the cattle presented for castration were about a year or older. Old bulls have very large cords that may not be easily occluded by circumferential in situ cord ligation. Additionally, unlike during controlled experiments, practitioners are likely to miss or incompletely ligate the cords. We therefore recommended that older animals, especially bulls about a year or older should not be castrated using the pinhole method for fear of castration failure. However, it should be noted that up to $94 \%$ of the seemingly non-atrophied were indeed hydrocele with atrophied dysfunctional testes. Again, this is the first report of hydrocele formation in ruminants arising from pinhole castration.

Histologically, all the atrophied testes showed extensive fibrosis with loss of normal tubular and interstitial architecture, and absolutely no evidence of spermatogenesis. All previous experiments to evaluate pinhole castration in bulls, dogs, goats made similar observations (Ponvijay, 2007; Okwee-Acai et al., 2013; Abid and Al-Baghdady, 2013). This is because if properly applied, in situ spermatic cord ligation induces ischemia necrosis resulting in fibrosis of both tubular and interstitial parenchyma hence loss of testicular function (Abid and Al-Baghdady, 2013). Thus, the procedure is an effective alternative to knife castration. 

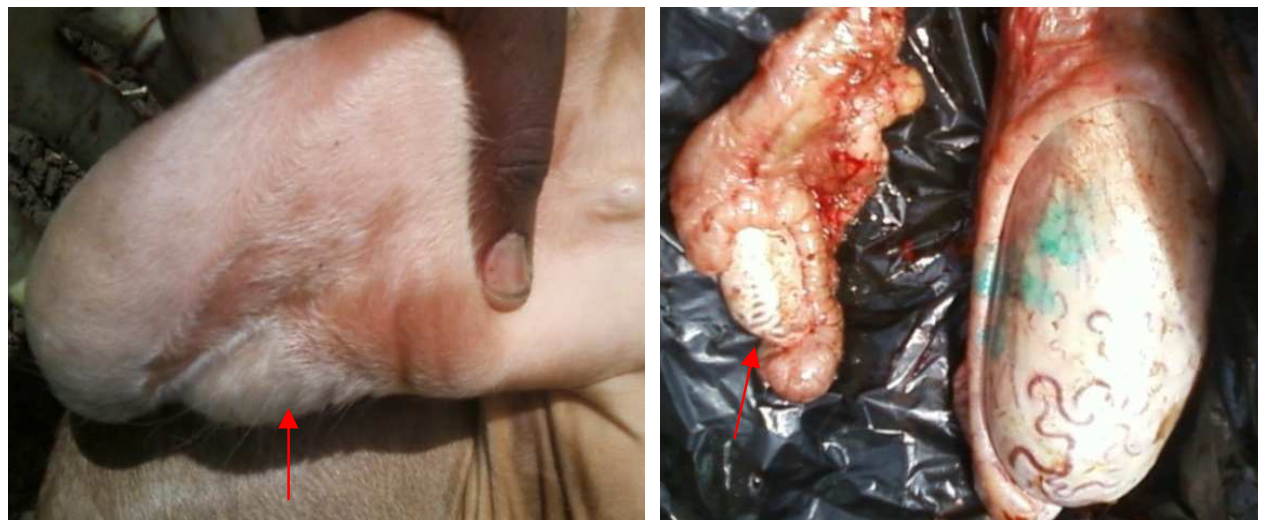

Fig. 5: Photograph showing unilateral testicular atrophy; Note the much smaller atrophied right testis (arrows), compared the much larger (less atrophied) left testis.
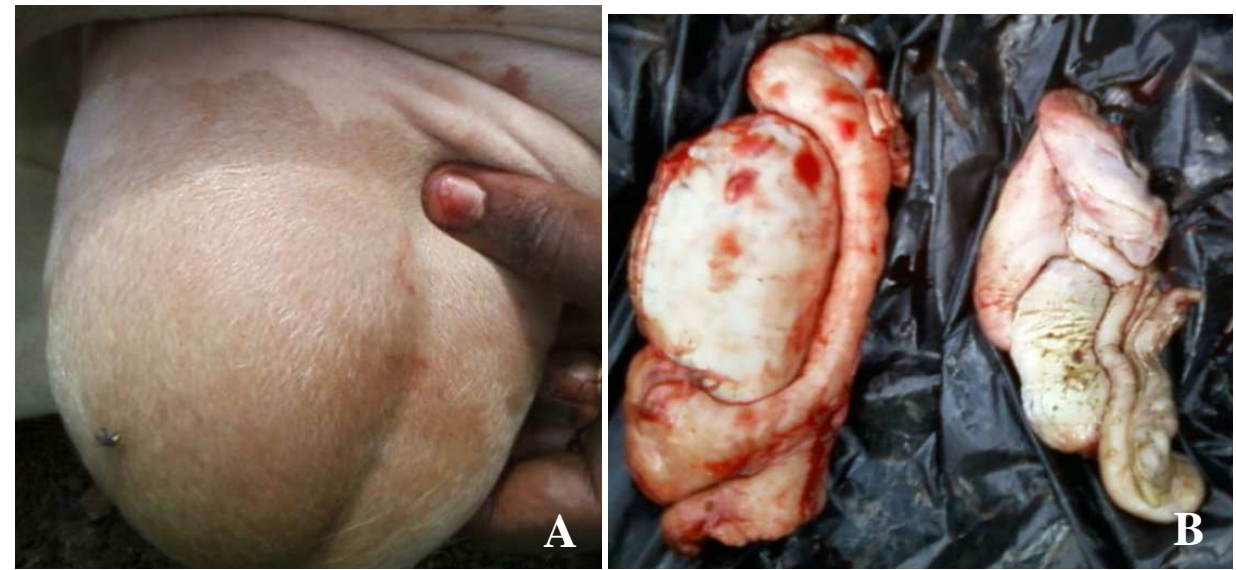

Fig. 6: Photographs showing Hydrocele following pinhole castration: Note the distended fluid-filled scrotal sacs (A) containing much atrophied and dysfunctional testes, B
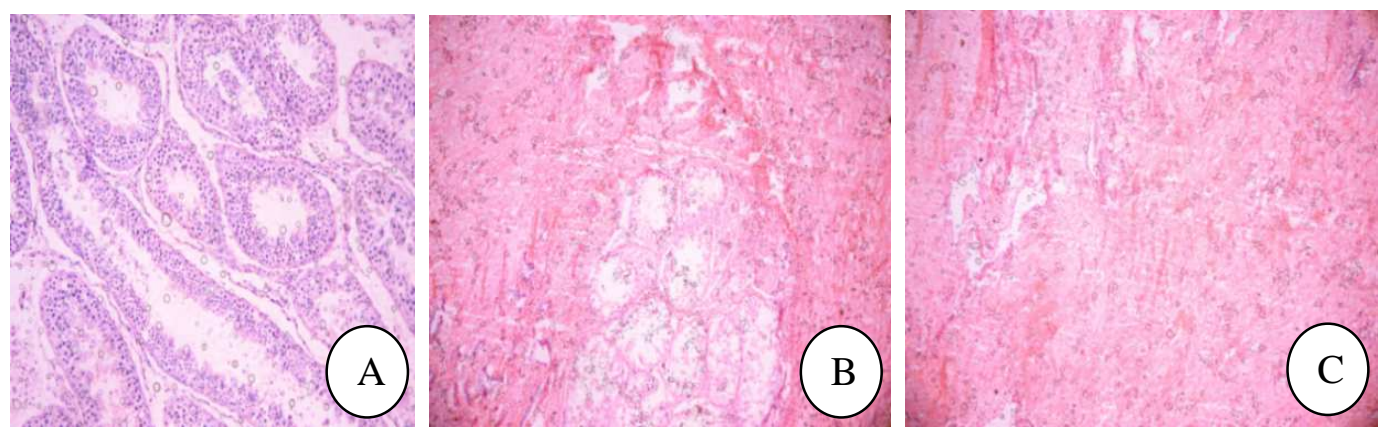

Fig. 7: Micrographs through goat testicular parenchyma: Note the tubular architecture of a normal testis (A), compared to a completely fibrous arhitecture in $\mathrm{B}$ and $\mathrm{C}$ of pinhole castrated goats.

We conclude that pinhole castration is indeed effective, minimally invasive, cheap and simple, and, may hence be adopted for mass castration of kids and calves especially in resource poor communities. However, because of hydrocele formation and non-atrophy in some cases, we recommend that the technique should not be applied in bulls that are about a year or older.

\section{Acknowledgment}

This study was funded in part by the Swedish International Development Cooperation Agency (Sida) and Makerere University. The funders, however, had no role in study design, data collection and analysis, and the decision to publish or the preparation of this manuscript. 


\section{References}

Abid TA, Al-Baghdady EF (2013). Evaluation of Pinhole Castration Technique in Iraqi Black Local Breed Bucks: Morphological and Histological Assessment. J Anim Vet Adv 12: 423-427.

Abou-Ahmed HM, EL-Kammar MH, EL-Neweshy MS, Abdel-Wahed RE (2012) Comparative evaluation of three in situ castration techniques for sterilizing donkeys: incision-ligation (a novel technique), section-ligation-release and pinhole. J Equine Vet Sci 32: 711-718.

Ames NK (1988) The male genital system: Sheep and goats. In: Textbook of Large Animal Surgery. $2^{\text {nd }}$ Edition, Oehme, WF (Ed.), Williams and Wilkins, Baltimore, USA, pp: 544-548.

Anderson D, Smith J (2003) Surgical Nursing. In: Veterinary Nursing, $3^{\text {rd }}$ Edition (Lane DR, Cooper B (Editors), Elsevier Science, London. pp: 503-557.

Baba MA, Fazili MR, Athar H, Mir MS, Moulvi BA, Khan I (2012) Comparison of the analgesic effects of meloxicam and those of ketprofen in male stay dogs undergoing pinhole castration. Asian J Anim Sci 6: 164-173

Baba MA, Fazili MR, Athar H, Mir MS, Moulvi BA, Khan I (2013) Pinhole Castration technique: An alternative to orchiectomy in stray dogs. Anim Reprod Sci 37: 113-118.

Coetzee JF, Nutsch AL Barbur LA and Bradburn RM (2010) A survey of castration methods and associated livestock management practices performed by bovine veterinarians in the United States. BMC Vet Res 6: 12 doi:10.1186/1746-6148 -6-12. http://www.biomedcentral.com/1746-6148/6/12

Harari J (2004) Wound healing. In: Small Animal Surgery Secrets, 2nd (Ed.), Hanley and Belfus, Philadelphia. pp: 1.

Jana K, Samantra PK, Gosh D (2005) Evaluation of single intra-testicular injection of calcium chloride for non-surgical sterilization of male black Bengal goats: A dose dependent study. Anim Reprod Sci 86: 89-108.

Melches S, Mellema SC, Doherr MG, Wechsler B, Steiner A (2007) Castration of lambs: A welfare comparison of different castration techniques in lambs over 10 weeks of age. Vet J 173: 554-563.

Molony V, Kent JE, Robertson IS (1995) Assessment of acute and chronic pain after different methods of castration of calves. Appl Anim Behav Sci 46: 3148.

Okwee-Acai J, Akunu B, Agwai E, Ekakoro E, Sajjakambwe P, Acon J (2012) An evaluation of stress responses, simplicity and cost of pinhole castration as an alternative technique for male dog sterilization. Res Opin Anim Vet Sci 2: 55-59.

Okwee-Acai J, Omara R, Onyait JS, Agwai B and Acon J (2013) An evaluation of pinhole castration as an alternative technique for dog population control in resource poor communities. Bull Anim Health Prod Afr 61: 337-345.

Okwee-Acai J, Acon J, Okello-Owiny D, Agwai B and Oloya J (2008) Evaluation of pinhole castration as an alternative technique for goat sterilization. Bull Anim Health Prod Afr 56: 299-306.

Ponvijay KS (2007) Pinhole Castration: A novel minimally invasive technique for in situ spermatic cord ligation. Vet Surg 36: 74-79.

Prunier A, Bonneau M, Borell EH, Cinotti S, Gunn M, Fredriksen B, Giersing M, Morton DB, Tuyttens FAM and Velarde A (2006). A review of the welfare consequences of surgical castration in piglets and the evaluation of non-surgical methods. Anim Welfare 15: 277-289.

Stafford KJ, Mellor DJ (2005) The welfare significance of the castration of cattle: a review. New Zealand Vet J 53: 271-278.

Wu FC (1988) Male contraception: Current status and future prospects. Clinical Endocrinol 29: 443-465. 